\title{
"Seeking the Noise in the Depth of Silence": A Naval Prelude with Spectators, 1665
}

John Dryden opens his Essay of Dramatick Poesie (1668), one of the birth documents of English literary criticism, with a scene of naval warfare that establishes a connection between an event of the utmost political and economic importance and the effect that such an event has on the public as it occurs:

\begin{abstract}
It was that memorable day, in the first Summer of the late War, when our Navy ingag'd the Dutch: a day wherein the two most mighty and best appointed Fleets which any age had ever seen, disputed the command of the greater half of the Globe, the commerce of Nations, and the riches of the Universe. While these vast floating bodies, on either side, mov'd against each other in parallel lines, and our Country men, under the happy conduct of his Royal Highness, went breaking, by little and little, into the line of the Enemies; the noise of the Cannon from both Navies reach'd our ears about the City: so that all men, being alarm'd with it, and in a dreadful suspence of the event, which they knew was then deciding, every one went following the sound as his fancy led him; and leaving the Town almost empty, some took towards the Park, some cross the River, others down it; all seeking the noise in the depth of silence. (Dryden 1971, 8)
\end{abstract}

'The public' as a site of social observation and self-reflection, theatrical in its flexible formations of actors and spectators, has only recently emerged as a dimension of collective awareness among the upper ranks of Restoration London's population, expressing itself in patriotic terms, mediated by newspapers, coffee-house conversations, and plays (Schweikart 1986, 63-70; Frank 1961; Pincus 1995). Public curiosity about the Battle of Lowestoft (3 June 1665), a naval engagement that remains invisible because it happens offshore and is yet barely audible in London, is motivated by a patriotic impulse, registered in Dryden's use of the first person plural in reporting and even in recording sense perceptions (“our Navy”, "our Country men”, "our ears”). This impulse is the result of a new social awareness outside of traditional notions of court and commonwealth that articulates itself in nationalist and incipiently imperial terms ("the riches of the Universe"). ${ }^{1}$ The disintegration of the traditional social order in the violent upheavals of Reformation, Civil War, and the English Republic seems all but forgotten in this new language of national unity after 1660.

But Dryden's text does more than observe the common and unifying impulse of public curiosity; it also registers a social reality of disintegration, dissociation, dispersal, and individualisation contingent upon it. As a consequence of the public desire of news, "the Town" - centre stage for dramatic events and public communication is left "almost empty". This depletion of the public sphere is noted in a series of subtle

1 On Dryden's fusion of the aesthetic and the political in the Essay, see Docherty 1999; on his careful manipulation of discursive levels, see Gelber 1999, 44-45.

๑ Open Access. ( 2020 Ingo Berensmeyer, published by De Gruyter. (G) BY-NC-ND This work is licensed under a Creative Commons Attribution-NonCommercial-NoDerivatives 4.0 International License. 
linguistic shifts, first to the third person plural ("they knew") and then to the third person singular ("every one went following the sound as his fancy led him"). The effect of dissociation into smaller groups ("some [. . .], some [. . .], others"), is just barely compensated for at the end in the word "all" that emphasises a common goal of "seeking the noise in the depth of silence".

This short extract anticipates some of the topics and concerns of this study. Dryden's paragraph can be read as a mise en abyme of seventeenth-century English culture and its fundamental problems. Not only does it point to the interdependence of literary and current political events and more long-term historic developments, namely the impending globalisation of economically motivated imperialism; it also reflects an awareness of the public dimension of political processes. To open an essay on the theatre with a modern variant of teichoscopy (the witnessing of an offstage event in ancient Greek literature) is to associate theatrical and political culture in more than a simple analogy. From the very beginning, Dryden problematises the relation of a performance (political as well as theatrical) to its intended audience; indeed, drama at this time could still be presented as a predominantly aural rather than visual form (Milhous 1984, 42). He knows that a battle has more dimensions than two ("Country men" vs. "Enemies") and that its interpretation crucially depends on the spectator's or listener's perspective. The situation of his public battle-listeners resembles the topos of curiosity as analysed by Hans Blumenberg $(1991,1996)$. He also knows that a public audience is fragmented into many smaller groups who are driven by individual interests and subjective, perhaps irrational motivations ("fancy"). The essay as a whole is constructed in a dramaturgical manner that casts the reader in the role of a spectator who follows the movements and the dialogue of four disputants: Eugenius, Crites, Lisideius, and Neander. Rhetorically, the first paragraph attempts to include the contemporary reader in a network of shared values and interests by appealing to a shared memory: "It was that memorable day [. . .]", and by including the reader in the first person plural, imputing to him (and, by 1668 , increasingly to her as well ${ }^{2}$ ) a shared nationality and shared experiences, which in their turn serve as a postulated common ground supporting Dryden's argument, in the Essay, for a specific national taste. Literary and political matters are thus inextricably, yet strategically, intertwined.

But the paragraph not only contains a patriotic appeal to a new sense of Englishness as a unifying attribute transcending minor issues of disagreement and division, modelled in contrast to perceptions of foreigners - Dutch, French - as insurmountably different. In its indecisive use of pronouns and grammatical persons, as well as in its shifting narrative focalisation, the text also implicitly reflects on the problems that arise in understanding and describing public opinion as a basis of modern politics and a modern conception of the state. Most importantly, such an

2 Female literacy grows significantly in the late sixteenth and throughout the seventeenth century. See, for example, Cressy 1980, 176-77; Pearson 1996; Wheale 1999, 105-31; Zwicker 2003, 311. 
understanding has to grapple with the philosophical and political problem of reconciling the one and the many, unity and multitude, private and public interest (Gunn 1969; Schweikart 1986). How must a political order be constructed and maintained that is capable of uniting the separate and distinct bodies of individuals and groups of individuals, each motivated by distinct interests or irreducible passions, "every one [. . . ] as his fancy led him", in a single body politic - defined by Hobbes as "the union of many men" $(1994,167 ; 2.27 .7)$ - propelled and stabilised by a single sovereign purpose?

Hobbes famously attempts to solve this problem by means of a language of representation $(1996,114 ; 1.16)$ :

A Multitude of men, are made One Person, when they are by one man, or one Person, Represented; so that it be done with the consent of every one of that Multitude in particular. For it is the Unity of the Representer, not the Unity of the Represented, that maketh the Person One. And it is the Representer that beareth the Person, and but one Person: And Unity, cannot otherwise be understood in Multitude.

This problem of the multitude and its unity - or otherwise - is one of the key issues of seventeenth-century English politics and culture. As Dryden well knew, a centralised, hierarchical social order could work very efficiently in military operations ("our Country men, under the happy conduct of his Royal Highness"), but it was much harder to maintain when a public 'we' was prone to disintegration into ever smaller divisions, when people were running in different directions even as they seemed to be pursuing a common goal. This difficulty would become manifest in the subsequent fate of "his Royal Highness", the Duke of York and later King James II, who was forced to abandon his throne and flee the country in 1688, an escape that was later reinterpreted as an act of abdication in order to legitimise the new monarch, William of Orange, as King William III.

What role do literature and rhetoric play in the formation of the body politic? Dryden does not expressly address this question, but his self-conscious use of rhetorical figures (which call attention to themselves, to their own mode of operation) can be taken as eloquent on this issue. The Essay of Dramatick Poesie stages a discussion about literary theory against the background of the Battle of Lowestoft, the most decisive victory of the English in all three Dutch Wars in the seventeenth century, thus connecting international politics to national poetics and loosely suggesting the advantages of (English) heterogeneity and mixed modes over (French) absolutism in literature as well as politics (Kroll 2002, 25-26). Like many authors of his time, Dryden could take for granted the decipherability of many levels of allusion, could trust in his reader's ability to seek out the "noise in the depth of silence", that place where the text reflects on its own operative conditions and strategies.

The necessity and rationality of such strategic language use and its reflection is indirectly established by the last paragraph of the essay, which completes its narrative frame. The battle is over, but the process of dispersal that the first paragraph 
wished to contain is intensified rather than stopped, as the text ends with the abrupt dissolution of the quartet of disputants: "Walking thence together to the Piazze they parted there; Eugenius and Lisideius to some pleasant appointment they had made, and Crites and Neander to their several Lodgings" (Dryden 1971, 81). The Italian word piazza was a common name for the North and East sides of Covent Garden. Its choice as the final scene of Dryden's essay underscores the modernity of his setting and his literary-political thought. Covent Garden had been built in 1631 outside the City limits, signalling the spread of a newly elegant lifestyle of conspicuous consumption (McKendrick et al. 1982, Burke 1993), and the demise of the older social order in which rich and poor had been living side by side in the City parishes. It virtually embodied the economic force of secularisation because the site on which it was erected was the site of Westminster Abbey's convent garden. As Simon Jenkins explains $(1975,28)$, “[t]he Convent Garden piazza was an instant success and it immediately led to the development of the surrounding streets. [. . .] Leading courtiers poured in applications for the gracious houses overlooking the square." The piazza is a theatrical space for social self-presentation and self-reflection, emblematic of a new understanding of society that is capitalist both in its economic, consumerist outlook and in its focus on the capital of London as a social stage. Its neoclassical Palladian architecture, designed by Inigo Jones, is a result of urban planning, not of haphazard growth: "elegant, uniform façades, instead of [. . . ] fiercely idiosyncratic and 'misshapen' houses” (Picard 1997, 24). Covent Garden is the fit emblem of Neander's (and Dryden's) dramatic ideals as well as of the social ideals of its time, praising elegant uniformity above 'ugly' idiosyncrasy in spectatorial, theatrical, and aesthetic (but above all visual) terms.

Strikingly, Dryden's use of the Italian word for 'square' - following popular usage also resonates with an allusion to Italian Renaissance humanism and republican political thought, which may well sound ironic in the political climate of later Stuart England: a typical witticism that downplays its challenge to royal prerogative, but which, despite its tongue-in-cheek mockery of democratic politics, does not fail to register the rise in political power of public opinion and early modern media in the second half of the seventeenth century - which was to come into its own in the Exclusion Crisis and the ravages of the Popish Plot scare of the late 1670s and early 1680 s.

While the public square (forum, piazza) is a place of meeting, of contact, transit, exchange and trade, it is also, as Dryden's essay accentuates, a place of separation, distinction, and individualisation. Milton, in Areopagitica (1644), uses it to describe the public nature of printed texts and to make fun of the baroque licensing practices of the Catholic church: "Sometimes 5 Imprimaturs are seen together dialogue-wise in the Piatza of one Title page" (Milton 1953b, 504). The printed text is a public square (or rectangle). For the theatre - and, by extension, for any text understood as a cultural event or performance occurring in a 'public sphere' (Habermas 1989) - this duality is important, perhaps decisive for understanding the role of media, and the relations between authors, texts, and readers in early modern culture. The public sphere is a place 
of difference as well as unity, a place - in more theoretical terms - that embodies the unity of different observations and representations. It creates distance and enables a more flexible management of distinctions (see Luhmann 1984, 597). From a Luhmannian perspective, one could describe the early modern public sphere as a first step towards the evolution of social systems. It is a place where public and private discourses, shared values and contested agreements, representations and figurations of social reality, mediations of power and lived lives meet, perhaps to intersect or intertwine, perhaps to differentiate and dissociate again, "to their several Lodgings"; but none of them will remain completely unchanged in the process. The public sphere emerges in the mid-seventeenth century as the very opposite of earlier representations of social coherence as a 'commonwealth' or 'common-weale' that postulated a "central fusion in an ultimate unity" (Luhmann 1984, 599).

Although Jürgen Habermas locates the emergence of a public sphere in the eighteenth century, there are good arguments for placing it in the seventeenth - even though not necessarily on Habermas's rationalist terms (see Pincus 1995; Achinstein 1994, 9). Despite its limitations, Habermas's model of the public sphere has the merit of connecting political theory with literary history and media studies, broaching a wider perspective on "phenomena that have been underplayed in revisionist historiography" (Norbrook 1994, 6) while "complicating the stereotyped notions of Renaissance individualism and bourgeois humanism that are still found in many current narratives of early modern subjectivity" (8). Early modern tensions between unity and disunity in the public sphere are prominent, for instance, in the conflict between commerce and virtue in republican theory (as analyzed by J. G. A. Pocock), but they can also be made visible in the lack of "clear-cut distinctions [. . .] between a 'modern' rationality, the classical discourse of civic phronesis, and the apocalyptic Protestant belief in progressive revelation" (Norbrook 1994, 10). ${ }^{3}$

In the emergence of the early modern public sphere and in the socio-cultural transformations of the republic of letters, all kinds of text (whether handwritten, scribally published, printed, spoken, recited or staged) functioned as key media of social exchange and reflection. Inasmuch as they reflect on the consequences of new technologies of public communication, they also become contributing factors in these transformations and media upheavals. But before we can come to a historical outline of these transformations, we need first to establish a more general methodological perspective as a firmer ground on which to base such 'contextural' readings of historical texts as this study aims to provide.

3 On the concept of 'commonwealth' before Hobbes, see Sharpe 2000b, 38-123. 


\section{The Sensibility of Dissociation}

From today's perspective, the world of seventeenth-century England is strange and distant. It is, in the resonant phrase of Peter Laslett (1973), a "world we have lost", accessible only by means of documentary evidence and its interpretations. The preferences and dislikes of that world, its spotlights of attention and penumbra of neglect, its idioms and languages, problems and entertainments, even its material conditions of writing and reading are not ours (Goldberg 1990, Johns 1998, Brayman Hackel 2005), even though we may sometimes recognise (or imagine) suggestive familiarities and continuities. Furthermore, even though we may be able to locate the conceptual or material origins of modern cultural and political topics, values and obsessions in early modernity (e.g., Shakespearean drama; political economy; opera), to understand those origins requires historical analysis and an intellectual reconstruction of their conditions and contexts.

In a period as disturbed by violent religious and political conflict as the seventeenth century, what William Paulson (1988) has called the "noise of culture" (those elements that, for us today, are not easily translatable into information) must needs be greater than during less troubled historical periods. Although in many respects very different from our own time, the world and its descriptions that emerge from this noise still appear recognisable or at least amenable to reconstruction. It may be an audacious claim that, with the publication of Hobbes's Leviathan - certainly one of the 'noisiest' texts to appear in seventeenth-century England -, "the basic character of Enlightenment politics [and thus of modern politics] was already in place” (Tuck 1993, 348). But such statements, whatever their truth value, assert the importance of seventeenth-century English (in connection with Welsh, Scottish and Irish) developments for the history of modern European ideas and mentalities without simply confirming the Whiggish truism of England's role as a forerunner of modernisation. It is the very complexity of the picture that results from a closer inspection, this peculiar combination of familiarity and strangeness, that makes the English seventeenth century so difficult to label as a literary period - late Renaissance, early baroque, neoclassicism? and so fascinating in its multifaceted developments (Ezell 2018).

One of the challenges of this period is the fact that the later seventeenth century has no single genre that could aspire to the overarching cultural function of the novel in the nineteenth century, or of drama in the Elizabethan and Jacobean periods. What we find instead is an energetic, turbulent, and noisy multiplicity, a fascinating disorder and an unceasing circulation of different discourses. Between these discourses, there may be some contact, exchange, or overlap, but they never cohere or collapse into some form of unity. Literary communication and intellectual exchange in the seventeenth century are highly agonistic and full of conflict, transforming humanist reading habits of "admiring, annotating and absorbing texts" into "acts of contest and combat" (Zwicker 2003, 300). In this respect, Michel de Certeau's suggestions for "a polemological analysis of culture”, in its situational interaction between tactics and strategies 
(articulated by the operations of rhetoric) have proved a valuable theoretical asset for my approach (de Certeau 1984, xvii; cf. 34-42). In such a combative framework, literature is to a considerable extent a continuation of warfare by other means. Literary communication originates and emerges from a multiplicity of idioms and forms, some readily available, others newly minted, bringing into contact and conflict a dynamic variety of discourses from religion, politics, rhetoric, and science to economics and eroticism. The results of this turbulence may at times be mere noise, at times rich in information.

I proceed, then, from a model of literary communication that is based on the observation that speakers (or writers) can "frame" their own speech but in which "the utterance cannot wholly determine the response” (Pocock 1985, 34). In such a configuration, observations of reality are indexed as contingent, as subject to dissent and revision, as soon as (or even before) they are made. If contingency - social as well as epistemic - can be understood as a decisive defining attribute of modernity (Luhmann 1998), then this attribute may lend added significance to the description of the seventeenth century as 'early modernity'. What distinguishes its literary culture from previous configurations is that it manages to integrate observations of contingency into "a self-conscious procedure" of literary writing and reading (Patey 1984, 179), transforming contingency into a structural element as well as a subject matter of textual communication. Contingency - the sense that things might as well be different - becomes the epistemological foundation for a "politics of utterance" that sets forth a method of discourse (as well as a number of discourses on method), a set of "operational rules determining the relational usage of a language that has become uncertain of the real" (de Certeau 1986, 91). In other words: writers begin to come to terms, more systematically than before, with the uncertainty of putting reality into words, by making this uncertainty a pre-condition for writing and reading (Blumenberg 1979; see also Aarsleff 1982 and Kroll 1991 on the changing understanding of language and signification in the seventeenth century).

This development, of which English neoclassicism is a decisive stage, traces a trajectory from images of stability, coherence, and certainty towards a conceptual rhetoric of mobility, circulation, contingency, and probability. The description of this passage from late humanism to English neoclassicism between 1630 and 1700 is the predominant concern of this book. Without unduly claiming a teleological development, I think it is safe to say that these seventy years are an important chapter in the history of literature as aesthetic communication, marked off from other kinds of discourse as "a sharply defined and autonomous realm of written objects that possess an 'aesthetic' character and value" (McKeon 1987b, 36). T. S. Eliot famously described this historical process of separation and distinction as a "dissociation of sensibility" (1951 [1921], 288) - as the prehistory of what he inevitably understood as the fragmentation of the modern world. Yet, quite anachronistically, this “dissociation” presupposes a previously unified, undissociated 
sensibility. ${ }^{4}$ In contrast to Eliot, I see the prehistory of modern literature not as a unified field of discourse but as structured by manifold exchanges, circulations, and conflicts among different kinds of text, different situations of utterance, and different contexts of communication. The multiplicity of contingent perspectives that emerges from a closer examination of seventeenth-century discourse is better described as a sensibility of dissociation than as an undissociated sensibility.

The problem with Eliot's reading of metaphysical poetry not only illustrates the difference between New Critical and historicist readings (he is, after all, making a historical argument); it helps to envisage the wider problems of historical studies in framing access to texts from the past. As an initial theoretical presupposition, I see the necessity to conceptualise and historicise not only the concept of 'literature' but the modes of production and of access to literary texts, modes that are determined by what I call cultural contextures. As I will explicate below, these contextures can be described as functionally determined embeddings of situations of writing and reading in their material cultural surroundings. These surroundings, needless to add, are often no longer materially available to us; they are not less in need of interpretation than the literary texts themselves, and often not less subject to traditional distortions of perspective. Texts, contexts, and contextures form a continuum from which one must inevitably make critical selections and place one's own emphases. Moreover, these selections can only occur from 'angles of contingency', tied as they are to the inevitability of perspective, to the interpreter's own historical moment.

Taking as his cue a few verses from Hamlet (5.2.324-28), Stephen Greenblatt (2002, 19) sums up the New Historicist ideal of a non-teleological cultural history: "To write cultural history we need more a sharp awareness of accidental judgments than a theory of the organic; more an account of purposes mistook than a narrative of gradual emergence; more a chronicle of carnal, bloody, and unnatural acts than a story of inevitable progress from traceable origins." With regard to the seventeenth century, this emphasis on material contingencies rather than theoretical or ideological coherence seems particularly apt - whatever one may otherwise think of the benefits and drawbacks of the New versus Old Historicism (cf. Hume 1999). Various directions of historicism, both old and recent, have contributed to a critical examination of the scholarly vocabulary, enhancing awareness of the historical shifts in the meaning of key concepts such as 'humanity', 'nature', or 'taste'. Such awareness may help to indicate the limits of understanding the past in modern terms. The term 'culture', "one of the two or three most complicated words in the English language" (Williams 1983, 87), applied to the seventeenth century, cannot have the same elevated meaning that it had for the

4 For a critique of Eliot's position, see Kermode 1975. According to Kermode, Eliot applies what is essentially a modern theory of the poetic image, recognising or rather constructing in the metaphysical poets of the early seventeenth century precursors of an ideal 'undissociated' poet who unifies thought and feeling. See also now Collini 2019. 
nineteenth- and early twentieth-century bourgeois: a realm of ideas and ideals separate from the crude realities of class conflict. For the Victorian sage and critic Matthew Arnold, culture famously was the opposite of anarchy (1971 [1869]). Early modern English culture, by contrast, requires a more comprehensive, flexible, and plural, even somewhat anarchic definition that opens it up to encompass a variety of geographical, historical, mental, and political factors.

In The Interpretation of Cultures, Clifford Geertz $(1973,49)$ argued for a symbolic anthropology that defines culture, in cybernetic terms, as "a set of control mechanisms [...] for the governing of behaviour." For Geertz, as for Kenneth Burke (1957), cultural representations (artefacts, rituals, social display) ought to be read as signifying structures that embody sociopolitical norms, values, and codes. More recently, both literary critics like Greenblatt and (post-)revisionist historians like Kevin Sharpe have proposed a "cultural turn" in early modern literary and social history in terms similar to Geertz's (see Sharpe 2000b, 19, 392-414). This can be supplemented by a systems-theoretical perspective (Luhmann 1995, 31-54), interpreting cultural media (including literary texts) not merely as ideological vehicles of "power-knowledge" (Foucault 1980) but as objects that "talk back" (Bal 1999) because they are instruments of analysis and reflection in their own right.

Such a perspective cannot rely merely on the presumed factuality of historical evidence to interpret literary texts from the past in and on their own terms. Facts are not enough; they are the explanandum, not the explanans. "Theory", as R. S. Crane put it (1953, xiii), "is inescapable”, and so each generation of historians and critics needs to make its own selections and interpretations of the cultural archive. The archive is inert, passive; it requires what Aleida Assmann calls a "working memory" $(2008,100)$ in order to activate it for the present.

Very broadly speaking, literature can be examined from two different aspects: as product or process. To view literature as product is to look at the results of literature, by reading texts or reading authors' biographies where the text is understood as a self-enclosed work, an entity, a work of art maybe, which is autonomous from the rest of the world or other social systems. This autonomy of literature, meaning that literature is governed by its own rules and not by politics or other social codes, arises around 1800, in connection with ideas about the freedom of art and of speech. In the seventeenth century, by contrast, there is still censorship, and there are battles about state censorship of what is published, especially in print - this may be another reason why manuscript circulation was still a viable alternative (Love 1993). Literature in the seventeenth century is closely involved with other aspects of life; it is not just the final product of an author's individual efforts. Here, I am more interested in the processes of writing and reading these works; I am of course also interested in how the works themselves are shaped by the very situations from which they arise, but my main interest is in the workings of the literary system of the time; mine is a kind of systematic, if not systems-theoretical, 
approach to literary history as not just a series of masterpieces, but the result of numerous acts of human and sometimes non-human interaction or engagement.

I think that the multiplicity of communicative settings, situations, and media needs to be taken seriously and not to be hidden away by forcing such anachronistic concepts upon it as the modern distinction between 'fictional' and 'non-fictional' or between 'literary' and 'non-literary' texts (or contexts of utterance). Those distinctions arguably emerge in the professionalisation of a literary marketplace, beginning in the late seventeenth to early eighteenth century, but their imposition on an earlier period constitutes an unjustified simplification. Notwithstanding the fact that distinctions between 'kinds' of literary communication were very well known in early modern Europe, those distinctions were only very rarely used for meta-communicative reflection but were productive of "highly complex and flexible [. . .] uses of literary forms" (Lewalski 1986, 1; see also Colie 1973, Fowler 1982).

In other words, even scholars (like myself) attracted by a systems-theoretical vocabulary will have difficulties adapting their terminology to the period before 1700 . Before what they call 'the autonomy of a literary system' begins to be socially established, systems theorists have severe difficulties seeing anything of note in the way of 'literature'. But literary history of course begins long before 1700. It would certainly be a special challenge to develop such a theoretical access, but - like other scholars in this field - I have come to the conclusion that systems theory in its most familiar form is too rigid to do justice to the multifariousness of literary-cultural phenomena in the early modern period, where the boundaries among social 'subsystems' or separate fields of discourse (e.g. politics, religion, history, economics) are far from clearly drawn. I have therefore mostly discarded the technical vocabulary of 'literary systems theory' while retaining certain basic assumptions about communication and contingency.

In framing a theoretical and historical perspective from which to describe and analyse seventeenth-century literary culture, I have concentrated on a number of focal areas. To give a very general outline, I have chosen to describe the emergence of English neoclassicism, a cultural formation - arguably the first one in modernity that explicitly, in theory as well as practice, establishes functional boundaries of literary communication in relation to other media, other performative dimensions of culture. But its significance is far from exclusively and narrowly 'literary' in this respect: it is indeed the fundamental and coherent cultural orientation of eighteenth-century civility and sociability, and thus a formative condition of what has come to be known as the Enlightenment. To sketch the early history of this cultural formation in England, I have concentrated on four main areas of concern. First, there is the early history of neoclassicism in the vestiges of European humanism (chapter 2). Here, my focus is on the different literary strategies developed by Robert Burton and Sir Thomas Browne in response to their altered communicative situation. What are the forms in which contingency is envisaged; what is the cultural background against which these forms become visible; and in what ways do these writers respond to its 
cultural challenge? Chapters 3 and 4 then proceed to look (from different angles) at the moments of origin of neoclassical discourse in England, between Civil War and Restoration. First, I examine the embattled, polemic, and polemogenic distinction between literary and visual modes of cognition and communication in texts by Milton, Hobbes, Davenant, and Margaret Cavendish. This is followed by an enquiry into the problem of social (rather than epistemic) contingency, a problem that becomes visible in chapter 3 but needs to be dealt with in a wider historical context: the Civil War and its disruptions of older notions of commonwealth, and their progressive replacement by the conceptual idiom of the state. Here, in chapter 4, I give an outline of the intricate relations between literary culture and early modern politics, beginning with the cultural fiction of the 'state of nature' and the role of rhetoric as efficacious speech; this involves a critical reappraisal of the differences and commonalities between Milton and Hobbes. This is followed by an analysis of political allegory in pastoral discourse (Izaak Walton's Compleat Angler), and by an analysis of 'literary politics' in and around the cultural moment of the Restoration, an analysis which concentrates on the crucial issues of cultural memory, countermemory, and orchestrated acts of oblivion; my examples here are Dryden's Astræa Redux, Tuke's Adventures of Five Hours, and Milton's Paradise Lost. The crisis of cultural memory and literary politics in the Restoration is presented in a reading of Dryden's Absalom and Achitophel, a reading that sums up the concerns of chapter 4 by relating allegorical narrative (and its failure) to temporality and contingency.

The final chapter traces the neoclassical response to the problems of inwardness and individuality in relation to civility and social norms in the early modern public sphere. This chapter sets out to retrieve and sum up the major concerns of this study: first by providing a paradigmatic example of the evolution of contingent individuality in connection with politics, history, and textuality that sheds new light on the early history of the novel (Aphra Behn's Love-Letters between a Nobleman and His Sister); then tracing the consequences of the Lockean foundation of politics (in the second Treatise of Government) on potentially retractable principles of trust, agreement, and contract, principles which remain open to revision, in Congreve's The Way of the World. With an unsurpassed lightness of touch, this play, on the cusp of the eighteenth century, captures the neoclassical, polite 'angle of contingency' that is the new, post-1688 cultural standard. The cultural norm of politeness as a way of managing contingency (now both epistemic and socio-political) can then be gauged in its effectiveness by its presence even in the writings of dissenters (Bunyan, Defoe) who use it to avoid being classified as irrational enthusiasts - even religious dissent now comes to accept the Lockean “degrees of assent” (Locke 1979, 657-68; 4.16).

In sum, these enquiries into several paradigmatic examples of late seventeenthcentury English literary culture from Milton to Congreve and from Hobbes to Locke intend to provide an outline of the spectrum of neoclassical discourse and of the different "angles of contingency" of which literary culture in seventeenth-century England was 
capable - outlining a period that was to become formative in English and, indeed, European cultural history.

Some readers will find my selections and their relative proportion unusual, surprising, or somewhat arbitrary; others may find them already too conventional. I do share these readers' regret at having to omit any extended discussion of - for instance Shakespeare, Jonson, Donne, Herbert, Marvell, and Otway on the one hand or of John Taylor, Lucy Hutchinson, Anne Conway, Phineas Fletcher, and Nathaniel Lee on the other hand (both lists could be extended almost indefinitely), and it is sad to see even the better-known names - almost all except Shakespeare - slowly but steadily vanishing from undergraduate curricula. The period between Shakespeare and Swift or Defoe may not be under-researched, but it is definitely under-taught. But this book is not intended as another literary history of the seventeenth century, and lack of completeness - never to be achieved or desirable in any event - needs to be carefully weighed against the advantages of distinctive selections. Generally, I have chosen paradigmatic texts from a variety of genres for more detailed scrutiny instead of a 'complete works' approach to a single author or a structural historical description of the development of individual genres.

The theoretical grounds of this book will be laid out in the next chapter. They follow recent reconstructive and revisionist movements in the humanities, movements that have brought historical perspectives back into literary studies. Beyond the New Historicism, this study has been inspired by the somewhat unlikely combination of Cambridge School intellectual history, German media studies, and Luhmannian systems theory - although I hope this will not be too obvious as the book progresses. Readers averse to theory are encouraged to proceed directly to chapter 2. 